\title{
BMJ Open Step 4: stick or twist? A review of Respiratory Research asthma therapy
}

\author{
Mariel G Slater, ${ }^{1}$ Ian D Pavord, ${ }^{2}$ Dominick E Shaw ${ }^{3}$
}

To cite: Slater MG

Pavord ID, Shaw DE. Step 4: stick or twist? A review of asthma therapy. BMJ Open Resp Res 2016;3:e000143. doi:10.1136/bmjresp-2016000143

Received 19 April 2016 Revised 4 July 2016 Accepted 6 July 2016

\section{(a) CrossMark}

${ }^{1}$ Medical Department, Boehringer Ingelheim Ltd, Bracknell, Berkshire, UK ${ }^{2}$ Nuffield Department of Medicine Research Building, University of Oxford, Oxford, Oxfordshire, UK

${ }^{3}$ Division of Respiratory Medicine, University of Nottingham, Nottingham City Hospital, Nottingham, UK

Correspondence to Dr Dominick Shaw; dominic. shaw@nottingham.ac.uk

\section{ABSTRACT}

Many people with asthma do not achieve disease control, despite bronchodilators and inhaled corticosteroid therapy. People with uncontrolled asthma are at higher risk of an asthma attack and death, with mortality rates estimated at 1000 deaths/ year in England and Wales. The recent National Review of Asthma Deaths (NRAD) report, 'Why asthma still kills', recommended that patients at step 4 or 5 of the British Thoracic Society/Scottish Intercollegiate Guidelines Network (BTS/SIGN) guidance must be referred to a specialist asthma service. This article reviews the 2014 evidence base for therapy of asthma patients at BTS/SIGN step 4 of the treatment cascade, in response to key findings of the NRAD report and lack of preferred treatment option at this step.

\section{INTRODUCTION}

It is estimated that $\sim 300$ million people have asthma worldwide, with expectations that this figure will rise to 400 million by $2025 .{ }^{12}$ The severity of disease varies and patients with severe asthma (requiring treatment at steps 4 and 5 of the British thoracic Society/Scottish Intercollegiate Guidelines Network (BTS/ SIGN $)^{3}$ guideline) ${ }^{4}$ often suffer from a worse quality of life, asthma attacks, hospitalisations and are at higher risk of death. ${ }^{5}$ It is thought that $\sim 4 \%$ of people with asthma suffer from true severe refractory disease ${ }^{6}$ and studies have shown that this subgroup of patients impart a disproportionate pharmacoeconomic burden, with mean UK annual treatment costs reaching between £2912 and $£ 4217$ per patient. ${ }^{7}$

The goal of asthma treatment is to achieve disease control, which is assessed by clinical measures and risk (of an asthma attack and of medication side effects). Poor control is linked with asthma attacks, which in turn are associated with poor future control and healthcare usage. ${ }^{89}$ In the UK, it is estimated that $\sim 65 \%$ of patients on at least an inhaled corticosteroid (ICS) with a long-acting $\beta_{2}$ adrenergic agonist (LABA) (BTS/SIGN step 3 upwards) remain uncontrolled. ${ }^{10}$ Potential factors, other than severity of disease, that may lead to reduced control include poor inhaler technique, non-adherence to medication, exposure to trigger factors and incorrect prescribing.

According to the BTS/SIGN guidance, patients with uncontrolled asthma should have treatment intensified by escalating up the treatment steps until control is achieved for at least 3 months, at which point 'stepping down' treatment should be considered (figure 1). ${ }^{3}$ Patients at step 4 are uncontrolled, despite receiving at least $800 \mu \mathrm{g}$ ICS per day (beclometasone dipropionate (BDP) or equivalent) plus a LABA (or other controller medication such as theophylline if LABA is not deemed effective at step 3). Recommended treatment options at this step are: increasing the dose of ICS up to $2000 \mu \mathrm{g} /$ day; adding a leukotriene receptor antagonist (LTRA); theophylline; $\beta_{2}$ adrenergic receptor agonist tablet; tiotropium bromide soft mist inhaler. However, there is no algorithm to suggest which treatment should be tried first and it is unclear whether one treatment is more efficacious than another. Furthermore, it is important to try and achieve disease control without resorting to oral steroids which are linked with osteoporosis, adrenal suppression, weight gain and diabetes. ${ }^{11}$

Despite national and international evidence-based guidelines, the optimal management strategy in severe asthma is still unclear due to lack of robust clinical data. Here, we focus on treatment options at step 4, given the recent National Review of Asthma Deaths (NRAD) report recommendation for specialist referral ${ }^{12}$ and lack of clarity at this step (a review of pharmacological therapy at each individual treatment step has been published elsewhere). ${ }^{13}$

\section{METHOD}

A literature review of randomised controlled clinical trials (RCTs) of each asthma therapy recommended by the 2014 version of the BTS/SIGN guidelines at step 4 was 


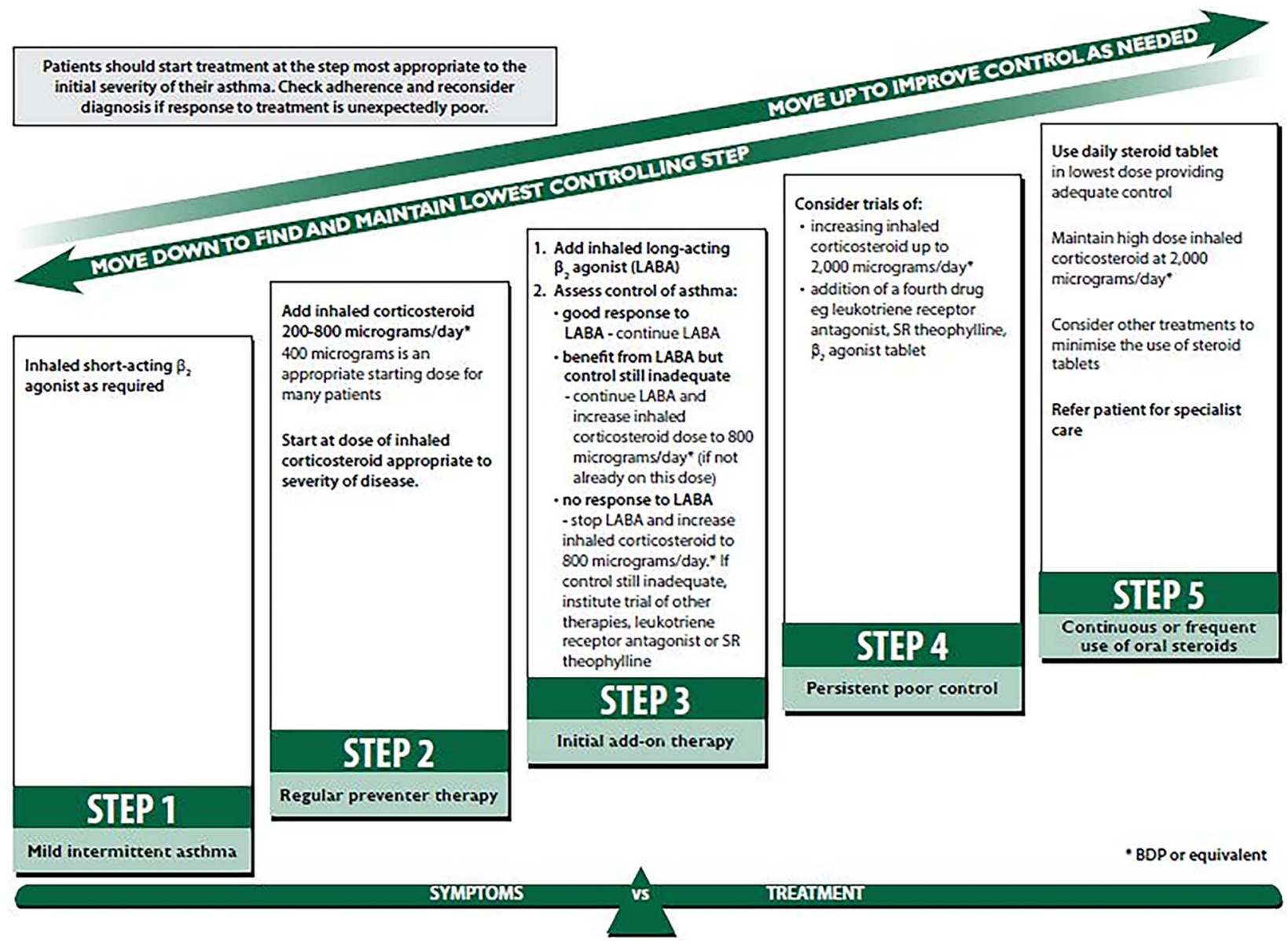

Figure 1 British thoracic Society/Scottish Intercollegiate Guidelines Network (BTS/SIGN) 2014 version of guidelines on the management of asthma: summary of stepwise management in adults. ${ }^{3}$ Reproduced from (SIGN 141: British Guideline on the Management of Asthma, BTS/SIGN, page 72, 2014) with permission from BMJ Publishing Group.

performed. Evidence included studies used to form the guideline itself (trials published to August 2012), RCTs and Cochrane reviews up to April 2016. Embase and MEDLINE were searched using the primary search terms 'asthma' (title) AND adult AND the therapy being assessed (title), for example, 'leukotriene receptor antagonist' OR 'pranlukast' OR 'montelukast' OR 'zafirlukast'. All ICS doses stated are BDP per day or equivalent $(\mu \mathrm{g}$ ) (low dose $<400 \mu \mathrm{g}$, medium $400-800 \mu \mathrm{g}$ and high dose $\geq 800 \mu \mathrm{g}){ }^{14}$

\section{TREATMENT OPTIONS AT STEP 4 OF THE BTS/SIGN GUIDELINES \\ Option 1: increasing the dose of ICS}

ICS are the cornerstone of asthma therapy and are used throughout steps 2-5 (figure 1). ${ }^{3}$ ICS exert their effects through binding to glucocorticoid receptors of inflammatory and structural cells within the airways, initiating cellular signalling and downregulation of inflammatory gene transcription and inflammatory mediator release, as well as upregulation of anti-inflammatory genes. ICS may also indirectly lead to bronchodilation, either through reduction in inflammatory cell obstruction or by increasing $\beta_{2}$ adrenergic receptor expression. ${ }^{15}$ Clinical trials in asthma have shown that ICS reduce exacerbations and short-acting $\beta_{2}$ adrenergic receptor agonist (SABA) use and also improve $\mathrm{FEV}_{1}$ and asthma symptoms, across a range of disease severities. ${ }^{16}$ However, side effects such as adrenal suppression become more common as the dose increases due to increased systemic exposure, ${ }^{17}$ and therefore, it is recommended that treatment is titrated to achieve the lowest dose possible to maintain disease control. ${ }^{3}$ It is thought that most clinical benefits from ICS occur at lower doses and that few patients benefit from doses above 400$800 \mu \mathrm{g}$, that is, the dose-response curve becomes flattened and side effects occur more frequently at doses above $800 \mu \mathrm{g}$ (figure 2). ${ }^{9}{ }^{17-21}$ However, some asthma patients, including smokers, ${ }^{22}{ }^{23}$ do respond clinically to higher doses of ICS, ${ }^{24}$ which can be accompanied by a normal serum cortisol level: ${ }^{25}$ consequently, no maximum effective dose can be defined.

\section{Evidence: increasing ICS up to $2000 \mu \mathrm{g}$}

One option is to increase the dose of ICS from $800 \mu \mathrm{g}$ to doses up to and including $2000 \mu \mathrm{g}$. As far as we are aware to date, there are no studies assessing the clinical 


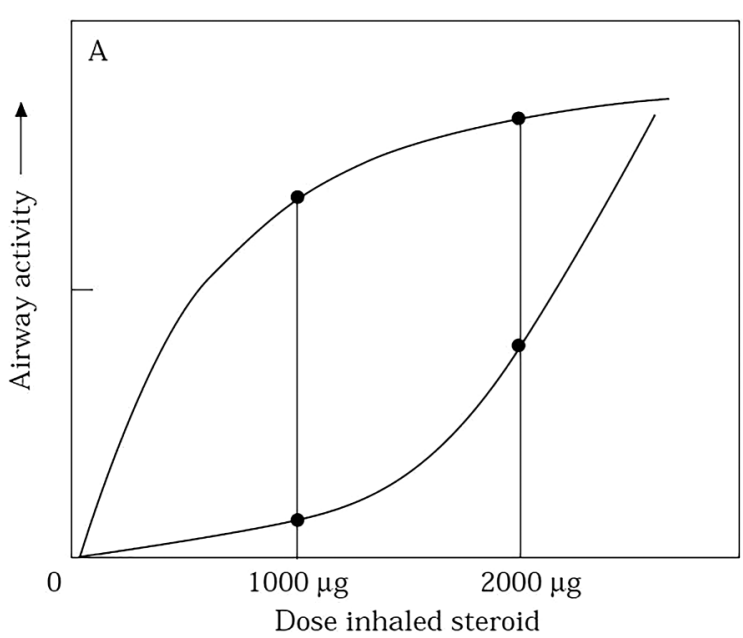

Figure 2 For most patients with asthma airway response becomes flatter after $1000 \mu \mathrm{g}$ of inhaled corticosteroid, but systemic activity (measured by serum cortisol levels) becomes steeper. ${ }^{17}$ Reproduced with permission from Professor Brian J Lipworth.

effectiveness of stepping up ICS in a step 4 patient population (already on high-dose ICS (without oral steroids) + LABA (or other add-on controller)), and the current guidelines are largely extrapolated from studies in patients at step $3 .^{326} 27$ It has not been established whether asthma patients on higher doses of ICS, for example, $1600 \mu \mathrm{g}$, are at lower risk of an asthma attack compared with those on $800 \mu \mathrm{g}$, and so clinical judgement with benefit/risk should guide this initial treatment choice.

\section{Option 2: add-on therapy with LTRA}

Leukotrienes are lipid mediators produced by inflammatory cells of the airways and are activated during allergic airway inflammation. Pathophysiological effects include bronchoconstriction, increased microvasculature permeability, mucus secretion and recruitment of eosinophils into the airway mucosa. Cysteinyl leukotriene (CysLT) inhibitors (montelukast, zafirlukast and pranlukast) can improve lung function, symptoms, SABA use, eosinophil level and exacerbation rate over a range of asthma severities in adults and children. ${ }^{28}$ One advantage of adding another anti-inflammatory medication to high-dose ICS is a potential steroid-sparing effect. LTRA may also inhibit early and late phase allergen responses, although the magnitude of effect on airway hyper-responsiveness (AHR) may be reduced in comparison with ICS. ${ }^{29}$

\section{Evidence: addition of LTRA compared with placebo/usual}

care

Although ICS are used first line as a single agent for asthma, ${ }^{30}{ }^{31}$ LTRA do have some beneficial effects when used with SABA alone ${ }^{27}$ and the BTS/SIGN guidance reference seven studies that suggest LTRA may have a modest effect on lung function, SABA use and asthma control over placebo. ${ }^{32}$ A meta-analysis of six studies of montelukast add-on therapy in mild-moderate asthma showed improved effectiveness compared with ICS alone, with regard to symptoms and chances of an asthma attack. ${ }^{33}$ However, there are no studies in the BTS/SIGN guidance that specifically assess the addition of LTRA as an add-on maintenance therapy at step 4 compared with placebo or usual care, and guidelines extrapolate from studies in milder patients.

More recent evidence includes a 6-week double-blind parallel group trial that assessed $80 \mathrm{mg}$ zafirlukast two times a day in 368 symptomatic asthma patients on highdose ICS $(\geq 1200 \mu \mathrm{g})$ plus any usual therapy. The results showed improved morning/evening PEF, daytime symptom score, SABA use and exacerbation risk with LTRA over placebo. ${ }^{34}$ A second study randomised 37 patients with symptomatic asthma already taking 800 $1200 \mu \mathrm{g}$ ICS plus a bronchodilator to $225 \mathrm{mg}$ pranlukast two times a day or normal care over 4 weeks, which resulted in improved lung function, asthma symptoms, SABA use and eosinophil levels in the pranlukast arm. ${ }^{35}$ A similar study assessed $10 \mathrm{mg}$ once daily montelukast as an add-on therapy to symptomatic asthma patients taking 400-1600 $\mu \mathrm{g}$ ICS over 16 weeks and showed increased asthma control and SABA usage compared with placebo. ${ }^{36}$ In contrast, two short-term clinical studies of patients on high-dose ICS $(\geq 1000 \mu \mathrm{g})$ showed no improvement in symptoms, lung function or SABA use with $10 \mathrm{mg}$ montelukast once daily ${ }^{37}$ Furthermore, a Cochrane review in adults and children with symptomatic asthma concluded that the addition of LTRA had a modest effect on lung function, but no effect on exacerbations requiring steroids. ${ }^{39}$ Although there is evidence to suggest that LTRA may be beneficial as an add-on therapy in step 4 patients, in difficult asthma, LTRA may only be beneficial in specific patients.

\section{Evidence: addition of LTRA compared with increasing the dose of ICS}

Several studies have compared LTRA add-on with increasing the dose of ICS, where addition to $800 \mu \mathrm{g}$ ICS seemed to be as efficacious as ICS doubling with regard to PEF, SABA use, symptom scores, exacerbations, AHR, eosinophil counts and quality of life. ${ }^{39-42}$ However, concomitant treatment with bronchodilators was not permitted in these trials and to the best of our knowledge, there are no studies specifically assessing LTRA as an add-on to high-dose ICS with a LABA compared with doubling/increasing the ICS dose. Therefore, comparative clinical effectiveness cannot be determined in a step 4 patient population.

\section{Option 3: add-on therapy with methylxanthines}

Theophylline is the most widely used methylxanthine and slow-release (SR) theophylline is recommended as a potential add-on therapy at step 4. Theophylline is a bronchodilator which exerts its effects by inhibition of phosphodiesterase III and IV, causing smooth muscle 
relaxation. Theophylline may also have other clinically relevant properties, including anti-inflammatory, immunomodulatory and bronchoprotective effects, ${ }^{43}$ potentially via mechanisms leading to increased histone deacetylase. ${ }^{44}$ SR theophylline was a popular treatment in the 1980s before concerns around toxicity led to reduced use: it has a narrow therapeutic index and serum concentration is linked with clinical benefits and drug toxicity. ${ }^{43}$ Side effects include gastric irritation, vomiting, palpitations and fall in blood pressure. ${ }^{45}$

\section{Evidence: addition of theophylline compared with placebo/ usual care}

Although recommended as an add-on therapy at step 4, there are no RCTs outlined in the BTS/SIGN evidence assessing efficacy in this population. A small study of 32 asthma patients on high-dose ICS (1096 $\mu$ g mean dose) plus other controller medication, referenced in the global initiative for asthma (GINA) report, found that the addition of theophylline improved lung function and asthma symptoms versus placebo. ${ }^{46}$ Since the BTS/ SIGN guideline publication, one study randomised 265 patients with asthma to high dose $(1000 \mu \mathrm{g})$ ICS/LABA combination plus $200 \mathrm{mg}$ theophylline two times a day or placebo for 24 weeks and described significantly fewer exacerbations in the theophylline arm $(30 \%)$ compared with placebo $(47 \%)$, as well as improved small airways function (forced expiratory flow (FEF) $25-75 \%$ ) and reduced sputum eosinophils; however, it is difficult to assess the impact of this study as patients were initially treatment naive and asthma control was variable. ${ }^{47}$

\section{Evidence: addition of theophylline compared with increasing the dose of ICS}

Two studies outlined in the BTS/SIGN guidance compared theophylline with increasing the dose of ICS. ${ }^{48}$ The first study, which is relevant only to step 3 patients, showed that 6 weeks of $250 \mathrm{mg}$ theophylline two times a day plus $400 \mu \mathrm{g}$ ICS had similar efficacy to $800 \mu \mathrm{g}$ ICS alone (lung function, symptoms and rescue medication use). ${ }^{49}$ The second 3-month study showed that $800 \mu \mathrm{g}$ ICS plus theophylline induced greater improvements in lung function compared with $1500 \mu \mathrm{g}$ ICS alone, with similar improvements in SABA reduction, variability of PEF and asthma severity. Furthermore, serum cortisol levels were significantly reduced in the $1500 \mu \mathrm{g}$ ICS arm. $^{50}$ Taken together, the addition of theophylline may have benefits over increasing the dose of ICS and may also act an effective steroid- sparing agent.

\section{Option 4: add-on therapy with $\beta_{2}$ agonist tablets}

Sustained-release oral $\beta_{2}$ agonist tablets, such as bambuterol (a prodrug of terbutaline), act through selective binding to $\beta_{2}$ adrenergic receptors on airway smooth muscle cells leading to smooth muscle relaxation. ${ }^{51}$ Although $\beta_{2}$ agonist tablets have a 24-hour bronchodilator effect, they are not widely used in a clinical setting and caution should be taken in patients already on
LABA. Common side effects associated with bambuterol include tremor, headache, heart palpitations, muscle cramps and sleep disturbances. ${ }^{52}$

\section{Evidence: addition of $\beta_{2}$ agonist tablets compared with placebo/usual care or increasing ICS dose}

Five clinical trials support the incorporation of oral $\beta_{2}$ agonist tablets into the BTS/SIGN guidelines as an add-on therapy at step 3 and step $4 .^{53}$ These studies assessed efficacy compared with inhaled salmeterol or oral salbutamol. In two studies, salmeterol was more effective than oral salbutamol with regard to PEF and need for rescue medication. ${ }^{54}{ }^{55}$ However, the remaining three studies showed that bambuterol was just as efficacious as inhaled salmeterol or oral salbutamol in outcomes, including PEF, $\mathrm{FEV}_{1}$, night-time awakenings, SABA use and symptoms. ${ }^{56-58}$ As far as we are aware there are no studies in step 4 patients assessing the efficacy of oral $\beta_{2}$ agonist tablets; (1) as an add-on therapy to usual care or (2) as an alternative to increasing the dose of ICS above $800 \mu \mathrm{g}$.

\section{Option 5: add-on therapy with tiotropium soft mist solution}

Tiotropium bromide is a long-acting (24-hour) muscarinic receptor antagonist (LAMA) that inhibits acetylcholine-mediated constriction of airway smooth muscle, through antagonism of $\mathrm{M}_{3}$ muscarinic receptors present on airway smooth muscle cells. ${ }^{59}$ This bronchodilator may also reduce mucus secretion, inflammation (potentially through inflammatory cell $\mathrm{M}_{3}$ receptor interactions) and airway remodelling. ${ }^{60-62}$ Tiotropium has been used as a maintenance therapy in chronic obstructive pulmonary disease for over a decade and increasing evidence has reported clinical effectiveness as an add-on therapy in asthma. ${ }^{63}$ Tiotropium is well tolerated ${ }^{64}$ with dry mouth being reported as the most common side effect. ${ }^{59}$ However, tiotropium may mask underlying inflammatory responses due to a bronchodilator effect and because no dual ICS/LAMA inhaler currently exists, the importance of ICS concordance must be emphasised.

\section{Evidence: addition of tiotropium compared with placebo/ usual care}

The BTS/SIGN guidelines report two RCTs of tiotropium in asthma, with one comparing tiotropium with placebo. In this study, 388 asthma patients who were not controlled on $400-1000 \mu \mathrm{g} \quad \mathrm{ICS} \pm \mathrm{LABA} \quad$ (step 3-4 patients) were randomised to tiotropium, placebo or salmeterol. The results showed that tiotropium $(5 \mu \mathrm{g}$ once daily, soft mist solution) was superior to placebo with regard to the primary outcome measure PEF, and was non-inferior to salmeterol $(50 \mu \mathrm{g}$ salmeterol two times a day) with similar adverse event rates. ${ }^{65}$ Since the 2014 BTS/SIGN evidence review, three more RCTs in asthma patients on medium-dose ICS have been published, all showing an improvement in $\mathrm{FEV}_{1}$ with $5 \mu \mathrm{g}$ once daily tiotropium over placebo. ${ }^{6-68}$ Two RCTs have been carried out specifically in step 4 patients: the first 8-week 
cross-over study investigated 2 doses of tiotropium ( $5 \mu \mathrm{g}$ and $10 \mu \mathrm{g}$ once daily) as an add-on therapy in 100 patients with severe asthma uncontrolled on at least $800 \mu \mathrm{g}$ ICS/LABA, and showed lung function significantly improved compared with placebo. ${ }^{69}$ The second phase III study compared the effects of $5 \mu \mathrm{g}$ tiotropium once daily with placebo in two replicate trials over 1 year in 912 patients with severe symptomatic asthma who had experienced at least one severe exacerbation in the previous year and were taking at least $800 \mu \mathrm{g}$ ICS plus a LABA. The peak and trough $\mathrm{FEV}_{1}$ significantly improved and there was a $21 \%$ reduction in risk of severe exacerbation and $31 \%$ reduction in asthma worsenings. ${ }^{70}$ In both studies, concomitant theophylline, LTRA and oral steroids were permitted at stable doses and subanalyses of the phase III trials showed clinical effectiveness was independent of allergic/inflammatory status and LTRA use. $^{71} 72$

\section{Evidence: addition of tiotropium compared with increasing the dose of ICS}

The second study outlined in the guidance was a crossover trial which assessed $18 \mu \mathrm{g}$ once daily tiotropium (dry powder suspension) compared with doubling lowmedium dose ICS in 210 patients with uncontrolled asthma. Tiotropium was superior to ICS doubling in terms of morning PEF, asthma control days, FEV1 prebronchodilator and daily symptom scores and was also non-inferior to salmeterol in most outcome measures, with $\mathrm{FEV}_{1}$ favouring tiotropium. ${ }^{73}$ However, this study was not in a step 4 population.

\section{DISCUSSION}

\section{Increasing the dose of ICS or add-on therapies: which one} and when?

Current therapeutic options at step 4 are generally based on dated clinical evidence, involving treatments from the $1960 \mathrm{~s}$ ( $\beta_{2}$ agonist tablets), 1970s (theophylline) and 1980s (LTRAs). ICS are considered the cornerstone of asthma therapy, however; increasing the dose of ICS is linked with side effects and a flattened dose-response curve. The 2014 BTS/SIGN guidance warns that theophylline and oral $\beta_{2}$ tablets are more likely to cause side effects compared with other treatments, with omission of $\beta_{2}$ tablets from GINA due to this increased risk. ${ }^{74}$ LTRA is an effective treatment in asthma, although it may be most useful in atopic patients due to mechanism of action. There are few RCTs of tiotropium, but these have shown efficacy at steps 3,4 and 5 of the treatment cascade, leading to incorporation into steps 4-5 of the GINA report. ${ }^{74}$ There are no large head-to-head trials in uncontrolled patients at this step, and therefore, treatment decisions should be made according to the evidence we do have and the potential for side effects.

\section{Other potential step 4 treatment options}

A low-dose ICS/LABA maintenance and reliever therapy regime may be more efficacious in reducing asthma attacks and hospitalisation, ${ }^{75}$ but may also increase exposure to ICS with unknown long-term safety effects. ${ }^{76}$ Anti-IgE therapy with the monoclonal antibody omalizumab has been shown to reduce exacerbation frequency and hospitalisations; however, treatment is expensive and is only indicated in a select group of patients. ${ }^{77} 78$ The recent development of monoclonal antibodies to cytokines involved in asthma pathophysiology has been encouraging, with mepoluzimab (an anti-IL-5 antibody which reduces exacerbations in exacerbation-prone patients with severe eosinophilic asthma ${ }^{79}$ receiving approval in the USA. However, new monoclonal antibodies mostly target a $\mathrm{Th}_{2}$ high asthma subtype ${ }^{80}$ and much like omalizumab before them, will be limited to use in patients with particular disease phenotypes and biomarker patterns.

\section{CONCLUSION}

The evidence for pharmacological therapy at step 4 of the 2014 BTS/SIGN asthma management strategy is limited and current use of asthma therapy at this stage in the clinic relies heavily upon small clinical trials, broad licence indications, extrapolation from mild and moderate disease and observational evidence. Clinical trials are required to inform which of these treatments to try first and whether or not there are asthma phenotypes associated with specific treatment responses. The new era of biologics is likely to change how we view asthma severity and the step-up/step-down paradigm outlined in the 2014 version of the BTS/SIGN guidance may become less relevant, with stratified and personalised medicine becoming more important in the management of step 4-5 asthma.

Contributors MS contributed towards the manuscript through inception, design, research, drafting and editing; IP contributed towards the manuscript through inception and editing and DS contributed towards the manuscript through inception, design, drafting and editing.

Funding This article had no funding other than publication fees provided by Boehringer Ingelheim.

Competing interests MS works as a medical science liaison manager within the medical department of Boehringer Ingelheim UK. IP reports speaker fees from Aerocrine, Almirall, Astrazeneca, Boehringer Ingelheim and GlaxoSmithKline and advisory board fees from Aerocrine, Almirall, Astrazeneca, Boehringer Ingelheim, Genentec, GlaxoSmithKline, Novartis, Regeneron, Roche and Teva. DS reports speaker fees from Boehringer Ingelheim, GlaxoSmithKline and Novartis and conference travel from GlaxoSmithKline and Novartis.

Provenance and peer review Not commissioned; externally peer reviewed.

Data sharing statement No additional data are available.

Open Access This is an Open Access article distributed in accordance with the Creative Commons Attribution Non Commercial (CC BY-NC 4.0) license, which permits others to distribute, remix, adapt, build upon this work noncommercially, and license their derivative works on different terms, provided the original work is properly cited and the use is non-commercial. See: http:// creativecommons.org/licenses/by-nc/4.0/

\section{REFERENCES}

1. Masoli M, Fabian D, Holt S, et al., Global Initiative for Asthma (GINA) Program. The global burden of asthma: executive summary of the GINA Dissemination Committee report. Allergy 
2004;59:469-78. http://www.ncbi.nlm.nih.gov/pubmed/15080825 (accessed 6 Apr 2004)

2. To T, Stanojevic S, Moores G, et al. Global asthma prevalence in adults: findings from the cross-sectional world health survey. BMC Public Health 2012;12:204.

3. British Thoracic Society; Scottish Intercollegiate Guidelines Network British guideline on the management of asthma. Thorax 2014;69 (Suppl 1):1-192.

4. Chung KF, Wenzel SE, Brozek JL, et al. International ERS/ATS guidelines on definition, evaluation and treatment of severe asthma. Eur Respir J 2014;43:343-73.

5. Department of Health. NHS atlas of variation in healthcare for people with respiratory disease. Department of Health, 18 July 2011. https://www.gov.uk/government/publications/an-outcomes-strategyfor-people-with-chronic-obstructive-pulmonary-disease-copd-andasthma-in-england (accessed 22 Feb 2016)

6. Hekking PP, Wener RR, Amelink M, et al. The prevalence of severe refractory asthma. J Allergy Clin Immunol 2015;135:896-902.

7. O'Neill S, Sweeney J, Patterson CC, et al. The cost of treating severe refractory asthma in the UK: an economic analysis from the British Thoracic Society Difficult Asthma Registry. Thorax 2015;70:376-8

8. Sullivan SD, Wenzel SE, Bresnahan BW, et al. Association of control and risk of severe asthma-related events in severe or difficult-to-treat asthma patients. Allergy 2007;62:655-60.

9. Bateman ED, Boushey HA, Bousquet J, et al. Can guideline-defined asthma control be achieved? The Gaining Optimal Asthma ControL study. Am J Respir Crit Care Med 2004;170:836-44.

10. Price D, Mathieson N, Mulgirigama A, et al. The burden of ICS/ LABA-treated asthma patients in the UK adult population. Thorax 2013;68(Suppl 3):P17.

11. eMC. SPC (summary of product characteristics): Lodotra $1 \mathrm{mg}, 2 \mathrm{mg}$ and $5 \mathrm{mg}$ modified-release tablets. Secondary SPC (summary of product characteristics): Lodotra $1 \mathrm{mg}, 2 \mathrm{mg}$ and $5 \mathrm{mg}$ modified-release tablets 3 February 2015. 2015. https://www. medicines.org.uk/emc/medicine/23778 (accessed 3 Feb 2015).

12. Levy ML. National Review of Asthma Deaths (NRAD). Br J Gen Pract 2014;64:564.

13. Patel M, Shaw D. A review of standard pharmacological therapy for adult asthma-Steps 1 to 5. Chron Respir Dis 2015;12:165-76.

14. Adams N, Bestall J, Jones PW. Budesonide at different doses for chronic asthma. Cochrane Database Syst Rev 2001;(4):CD003271.

15. Barnes PJ, Pedersen S. Efficacy and safety of inhaled corticosteroids in asthma. Report of a workshop held in Eze, France, October 1992. Am Rev Respir Dis 1993;148(Pt 2):S1-26.

16. Adams NP, Bestall JB, Malouf $R$, et al. Inhaled beclomethasone versus placebo for chronic asthma. Cochrane Database Syst Rev 2005;(1):CD002738.

17. Lipworth BJ. Airway and systemic effects of inhaled corticosteroids in asthma: dose response relationship. Pulm Pharmacol 1996;9:19-27.

18. Geddes DM. Inhaled corticosteroids: benefits and risks. Thorax 1992;47:404-7.

19. Powell H, Gibson PG. Inhaled corticosteroid doses in asthma: an evidence-based approach. Med J Aust 2003;178:223-5.

20. Szefler SJ, Martin RJ, King TS, et al. Significant variability in response to inhaled corticosteroids for persistent asthma. J Allergy Clin Immunol 2002:109:410-18.

21. Masoli M, Holt S, Weatherall M, et al. Dose-response relationship of inhaled budesonide in adult asthma: a meta-analysis. Eur Respir $J$ 2004:23:552-8.

22. Chalmers GW, Macleod KJ, Little SA, et al. Influence of cigarette smoking on inhaled corticosteroid treatment in mild asthma. Thorax 2002:57:226-30.

23. Tomlinson JE, McMahon AD, Chaudhuri R, et al. Efficacy of low and high dose inhaled corticosteroid in smokers versus non-smokers with mild asthma. Thorax 2005;60:282-7.

24. Adams NP, Jones PW. The dose-response characteristics of inhaled corticosteroids when used to treat asthma: an overview of Cochrane systematic reviews. Respir Med 2006;100:1297-306

25. Toogood JH, Lefcoe NM, Haines DS, et al. A graded dose assessment of the efficacy of beclomethasone dipropionate aerosol for severe chronic asthma. J Allergy Clin Immunol 1977;59:298-308.

26. BTS/SIGN. Guideline topic: Pharmacological management of asthma. Evidence table 4.4a: Inhaled corticosteroid vs theophylline. Secondary Guideline topic: Pharmacological management of asthma. Evidence table 4.4a: Inhaled corticosteroid vs theophylline 2014. http://www.sign.ac.uk/guidelines/published/support/ guideline63/table4.4a.html

27. BTS/SIGN. Guideline topic: Pharmacological management of asthma. Evidence table 4.4c: Inhaled corticosteroid vs leukotriene receptor antagonists. Secondary Guideline topic: Pharmacological management of asthma. Evidence table 4.4c: Inhaled corticosteroid vs leukotriene receptor antagonists 2014. http://www.sign.ac.uk/ guidelines/published/support/guideline63/table4.4c.html

28. Montuschi P, Peters-Golden ML. Leukotriene modifiers for asthma treatment. Clin Exp Allergy 2010;40:1732-41.

29. Leigh R, Vethanayagam D, Yoshida M, et al. Effects of montelukast and budesonide on airway responses and airway inflammation in asthma. Am J Respir Crit Care Med 2002;166:1212-17.

30. Ducharme FM. Inhaled glucocorticoids versus leukotriene receptor antagonists as single agent asthma treatment: systematic review of current evidence. BMJ 2003;326:621.

31. Chauhan BF, Ducharme FM. Anti-leukotriene agents compared to inhaled corticosteroids in the management of recurrent and/or chronic asthma in adults and children. Cochrane Database Syst Rev 2012;5:CD002314.

32. BTS/SIGN. Guideline topic: Pharmacological management of asthma. Evidence table 4.4d: Leukotriene receptor antagonists with short-acting beta-agonists. Secondary Guideline topic: Pharmacological management of asthma. Evidence table 4.4d: Leukotriene receptor antagonists with short-acting beta-agonists 2014. http://www.sign.ac.uk/guidelines/published/support/ guideline63/table4.4d.html

33. Joos S, Miksch A, Szecsenyi J, et al. Montelukast as add-on therapy to inhaled corticosteroids in the treatment of mild to moderate asthma: a systematic review. Thorax 2008:63:453-62.

34. Virchow JC Jr, Prasse A, Naya I, et al. Zafirlukast improves asthma control in patients receiving high-dose inhaled corticosteroids. Am J Respir Crit Care Med 2000;162(Pt 1):578-85.

35. Wada K, Minoguchi K, Kohno Y, et al. Effect of a leukotriene receptor antagonist, pranlukast hydrate, on airway inflammation and airway hyperresponsiveness in patients with moderate to severe asthma. Allergol Int 2000;49:63-8.

36. Vaquerizo MJ, Casan P, Castillo J, et al. Effect of montelukast added to inhaled budesonide on control of mild to moderate asthma Thorax 2003;58:204-10.

37. Robinson DS, Campbell D, Barnes PJ. Addition of leukotriene antagonists to therapy in chronic persistent asthma: a randomised double-blind placebo-controlled trial. Lancet 2001;357:2007-11.

38. Tonelli M, Zingoni M, Bacci E, et al. Short-term effect of the addition of leukotriene receptor antagonists to the current therapy in severe asthmatics. Pulm Pharmacol Ther 2003;16:237-40.

39. Ducharme F. Addition of anti-leukotriene agents to inhaled corticosteroids for chronic asthma. Cochrane Database Syst Rev 2011;(3):CD003133.

40. Price DB, Hernandez D, Magyar P, et al. Randomised controlled tria of montelukast plus inhaled budesonide versus double dose inhaled budesonide in adult patients with asthma. Thorax 2003:58:211-16.

41. Barnes N, Laviolette M, Allen D, et al. Effects of montelukast compared to double dose budesonide on airway inflammation and asthma control. Respir Med 2007;101:1652-8.

42. Riccioni G, Vecchia RD, D'Orazio N, et al. Comparison of montelukast and budesonide on bronchial reactivity in subjects with mild-moderate persistent asthma. Pulm Pharmacol Ther 2003:16:111-14.

43. Weinberger M, Hendeles L. Theophylline in asthma. $N$ Engl J Med 1996;334:1380-8

44. Cosio BG, Tsaprouni L, Ito K, et al. Theophylline restores histone deacetylase activity and steroid responses in COPD macrophages. J Exp Med 2004;200:689-95.

45. eMC. SPC (summary of product characteristics): Slo-Phyllin $60 \mathrm{mg}$ $125 \mathrm{mg}, 250 \mathrm{mg}$, Capsules. Secondary SPC (summary of product characteristics): Slo-Phyllin $60 \mathrm{mg}, 125 \mathrm{mg}, 250 \mathrm{mg}$, Capsules 10 November 2015. 2014. https://www.medicines.org.uk/emc/medicine/ 1047 (accessed 10 Nov 2015)

46. Rivington RN, Boulet LP, Cote J, et al. Efficacy of Uniphyl, salbutamol, and their combination in asthmatic patients on high-dose inhaled steroids. Am J Respir Crit Care Med 1995;151(Pt 1):325-32.

47. Nie H, Zhang G, Liu M, et al. Efficacy of theophylline plus salmeterol/fluticasone propionate combination therapy in patients with asthma. Respir Med 2013;107:347-54.

48. BTS/SIGN. Guideline topic: Pharmacological management of asthma. Evidence table 4.11d: Add-on drugs for inhaled steroids: Theophylline, beclomethasone diproponate, budesonide. Secondary Guideline topic: Pharmacological management of asthma. Evidence table 4.11d: Add-on drugs for inhaled steroids: Theophylline, beclomethasone diproponate, budesonide 2014. http://www.sign.ac. uk/guidelines/published/support/guideline63/table4.11d.html

49. Ukena D, Harnest $U$, Sakalauskas $R$, et al. Comparison of addition of theophylline to inhaled steroid with doubling of the dose of inhaled steroid in asthma. Eur Respir J 1997;10:2754-60. 
50. Evans DJ, Taylor DA, Zetterstrom O, et al. A comparison of low-dose inhaled budesonide plus theophylline and high-dose inhaled budesonide for moderate asthma. $N$ Engl J Med 1997;337:1412-18.

51. Waldeck B. Beta-adrenoceptor agonists and asthma-100 years of development. Eur J Pharmacol 2002;445:1-12.

52. eMC. SPC (summary of product characteristics): Bambec Tablets $10 \mathrm{mg}$. Secondary SPC (summary of product characteristics): Bambec Tablets 10mg 3 September 2014. 2014. https://www. medicines.org.uk/emc/medicine/9574 (accessed 3 Sep 2014).

53. BTS/SIGN. Guideline topic: Pharmacological management of asthma. Evidence table 4.11b: Add-on drugs for inhaled steroids: Long acting or oral B2 agonists. Secondary Guideline topic: Pharmacological management of asthma. Evidence table 4.11b: Add-on drugs for inhaled steroids: Long acting or oral B2 agonists 2014. http://www.sign.ac.uk/guidelines/published/support/ guideline63/table4.11b.html

54. Ringbaek TJ, Soes-Petersen U, Christensen M, et al. Salmetero improves the control of disease in patients with moderate asthma. A comparative study of inhaled salmeterol $50 \mathrm{mg}$ and salbutamol depot tablets $8 \mathrm{mg}$, both administered twice daily. Ugeskr Laeger 1996;158:3940-3.

55. Brambilla C, Chastang C, Georges D, et al. Salmeterol compared with slow-release terbutaline in nocturnal asthma. A multicenter, randomized, double-blind, double-dummy, sequential clinical trial. French Multicenter Study Group. Allergy 1994:49:421-6.

56. Crompton GK, Ayres JG, Basran G, et al. Comparison of oral bambuterol and inhaled salmeterol in patients with symptomatic asthma and using inhaled corticosteroids. Am J Respir Crit Care Med 1999;159:824-8.

57. Gunn SD, Ayres JG, McConchie SM. Comparison of the efficacy, tolerability and patient acceptability of once-daily bambuterol tablets against twice-daily controlled release salbutamol in nocturnal asthma. ACROBATICS Research Group. Eur J Clin Pharmacol 1995;48:23-8

58. Wallaert B, Brun P, Ostinelli J, et al. A comparison of two long-acting beta-agonists, oral bambuterol and inhaled salmeterol, in the treatment of moderate to severe asthmatic patients with nocturnal symptoms. The French Bambuterol Study Group. Respir Med 1999;93:33-8.

59. eMC. SPC (summary of product characteristics): Spiriva Respimat 2.5 microgram, inhalation solution. Secondary SPC (summary of product characteristics): Spiriva Respimat 2.5 microgram, inhalation solution 13 January 2015. 2015. https://www.medicines.org.uk/emc/ medicine/20134 (accessed 13 Jan 2015).

60. Bateman ED, Rennard S, Barnes PJ, et al. Alternative mechanisms for tiotropium. Pulm Pharmacol Ther 2009;22:533-42.

61. Kistemaker LE, Hiemstra PS, Bos IS, et al. Tiotropium attenuates IL-13-induced goblet cell metaplasia of human airway epithelial cells. Thorax 2015;70:668-76.

62. Moulton BC, Fryer AD. Muscarinic receptor antagonists, from folklore to pharmacology; finding drugs that actually work in asthma and COPD. Br J Pharmacol 2011;163:44-52.

63. Rodrigo GJ, Castro-Rodriguez JA. What is the role of tiotropium in asthma? a systematic review with meta-analysis. Chest 2015;147:388-96.

64. Haughney J, Vandewalker M, Meltzer E, et al. Once-daily Tiotropium Respimat $(\mathrm{A}$ : safety and tolerability results from five phase III trials in adults with symptomatic asthma [abstract]. Thorax 2014;69:A178-9: P231.

65. Bateman ED, Kornmann O, Schmidt P, et al. Tiotropium is noninferior to salmeterol in maintaining improved lung function in B16-Arg/Arg patients with asthma. J Allergy Clin Immunol 2011;128:315-22.

66. Kerstjens HA, Casale TB, Bleecker ER, et al. Tiotropium or salmeterol as add-on therapy to inhaled corticosteroids for patients with moderate symptomatic asthma: two replicate, double-blind, placebo-controlled, parallel-group, active-comparator, randomised trials. Lancet Respir Med 2015;3:367-76.

67. Ohta $\mathrm{K}$, Ichinose $\mathrm{M}$, Tohda $\mathrm{Y}$, et al. Long-term once-daily tiotropium Respimat ${ }^{\circ}$ is well tolerated and maintains efficacy over 52 weeks in patients with symptomatic asthma in Japan: a randomised, placebo-controlled study. PLOS ONE 2015;10:e0124109.

68. Timmer W, Moroni-Zentgraf P, Cornelissen P, et al. Once-daily Tiotropium Respimat $(\mathbb{B}) 5 \mu \mathrm{g}$ is an efficacious $24-\mathrm{h}$ bronchodilator in adults with symptomatic asthma. Respir Med 2015;109:329-38.

69. Kerstjens HA, Disse B, Schroder-Babo W, et al. Tiotropium improves lung function in patients with severe uncontrolled asthma: a randomized controlled trial. J Allergy Clin Immunol 2011;128:308-14

70. Kerstjens HA, Engel M, Dahl R, et al. Tiotropium in asthma poorly controlled with standard combination therapy. N Engl J Med 2012;367:1198-207.

71. Dahl R, Doherty D, Corren J, et al. Once-daily Tiotropium Respimat $\circledast$ improves lung function in patients with severe symptomatic asthma independent of leukotriene modifier use [abstract]. Thorax 2014;69:A178.

72. Murphy K, Pearlman D, Dahl R, et al. Once-daily Tiotropium Respimat $₫$ add-on to at least ICS maintenance therapy reduces airflow obstruction in patients with symptomatic asthma, independent of allergic status. J Allergy Clin Immunol 2015;135:AB6.

73. Peters SP, Kunselman SJ, Icitovic N, et al. Tiotropium bromide step-up therapy for adults with uncontrolled asthma. N Engl J Med 2010;363:1715-26.

74. GINA. From the global strategy for asthma management and prevention, Global Initiative for Asthma (GINA) 2016. 2016:1-147 (accessed 2 Jul 2016).

75. Kew KM, Karner C, Mindus SM, et al. Combination formoterol and budesonide as maintenance and reliever therapy versus combination inhaler maintenance for chronic asthma in adults and children. Cochrane Database Syst Rev 2013;12:CD009019.

76. Patel M, Pilcher J, Pritchard A, et al. Efficacy and safety of maintenance and reliever combination budesonide-formoterol inhaler in patients with asthma at risk of severe exacerbations: a randomised controlled trial. Lancet Respir Med 2013;1:32-42.

77. Normansell R, Walker S, Milan SJ, et al. Omalizumab for asthma in adults and children. Cochrane Database Syst Rev 2014;1: CD003559.

78. eMC. SPC (summary of product characteristics): Xolair 150mg solution for injection. 2015. https://www.medicines.org.uk/emc/ medicine/24912 (accessed 22 Feb 2016).

79. Liu Y, Zhang S, Li DW, et al. Efficacy of anti-interleukin-5 therapy with mepolizumab in patients with asthma: a meta-analysis of randomized placebo-controlled trials. PLOS ONE 2013;8:e59872.

80. Chung KF. Targeting the interleukin pathway in the treatment of asthma. Lancet 2015;386:1086-96. 